\title{
Homem e mulher no mercado de trabalho local: o caso do município de Montes Claros
} (MG)

\author{
Gilson Cássio de Oliveira Santos ${ }^{1}$
}

Resumo: O presente texto avalia o comportamento do mercado de trabalho em Montes Claros (MG) a partir da diferença entre sexos. As observações foram feitas por meio da análise exploratória, com base em estatística descritiva, utilizando dados da Relação Anual de Informações Sociais (RAIS) do Ministério da Economia. Percebe-se que as diferenças entre homens e mulheres no mercado formal de trabalho têm diminuído tanto no que diz respeito à participação de trabalhadores e trabalhadoras, quanto no que tange aos rendimentos. Porém, disparidades ainda persistem, fato que deve estimular o pensamento sobre políticas públicas que sejam efetivamente capazes de liquidar as discrepâncias entre sexos no tocante ao mercado de trabalho.

Palavras-chave: desigualdade entre homens e mulheres, mercado de trabalho, políticas públicas.

Abstract: The text presented here is a research report that evaluates the labor market behavior in Montes Claros (MG) from the gender difference. Observations were made from the exploratory evaluation, based on descriptive statistics, using data from the Ministry of Economy's Annual Report on Social Information (RAIS). It can be seen that the differences between men and women in the formal labor market have been decreasing both with regard to the stock of workers and with regard to income. However, disparities still persist, a fact that should stimulate public policy thinking that is effectively able to close gender gaps in the labor market.

Keywords: inequality between men and women, labor market, policies.

\footnotetext{
${ }^{1}$ Bacharel em Ciências Sociais e Mestre em Desenvolvimento Social pela Universidade Estadual de Montes Claros (UNIMONTES). Doutor em Sociologia pela Universidade Federal de Minas Gerais (UFMG). Atualmente é Sociólogo da UNIMONTES e Professor da Faculdade Santo Agostinho (FASA). E-mail: gilson.santos@unimontes.br.
} 


\section{Introdução:}

O desenvolvimento produtivo trouxe para a contemporaneidade formas instáveis de execução do trabalho. Nesse contexto, explicita-se o exacerbado crescimento do setor de serviços, o qual traz em si características claras de flexibilidade e de fragmentação; a intensa rotatividade de mão de obra; a diminuição dos rendimentos médios; e, além de vários outros pontos, o crescimento da ocupação feminina. Este último fator deve ser destacado aqui, uma vez que se pretende entender o comportamento de trabalho feminino em Montes Claros, Norte de Minas Gerais, observando o período de 1985 a 2015.

As perguntas norteadoras que se farão analisar são as seguintes: A ocupação feminina cresceu de fato em Montes Claros? E em que medida? Onde e o que fazem homens e mulheres no mercado de trabalho local? Os rendimentos delas estão se igualando ao rendimento deles?

O presente texto apresenta uma discussão sobre desigualdade, visto que desigualdades geram formas de exclusão, sendo a pobreza uma das mais debatidas. No entanto, o conceito de pobreza mostrase insuficiente para a representação das demais formas de exclusão que se tornam cada vez mais complexas.

Segundo Polanyi (2000), a pobreza é originária do desenvolvimento das relações de troca de mercadorias. Para ele, os pobres surgem após o nascimento da economia de mercado. Na explanação desse autor, observa-se que todos os grupos sociais, em todo o percurso da história, possuíram relações de troca, no entanto, anteriormente à economia de mercado, as relações sociais possuíam supremacia em relação às trocas materiais. O contrário disso ocorre posteriormente às articulações mercadológicas das sociedades, quando se institui a já mencionada "economia de mercado".

Polanyi ressalta ainda que, no contexto da economia de mercado, as relações sociais se subordinam às trocas de mercadorias. Sendo assim, tanto o indivíduo quanto a sociedade, e mesmo o Estado, articulam-se no sentido de atender às necessidades meramente mercadológicas, deixando em segundo plano, ou de forma dependente, as articulações sociais, culturais e políticas em detrimento das relações de mercado.

Está também, nessa perspectiva, a configuração das diversas faces da exclusão social existente no mundo atual. Nas palavras de Balsa, "as desigualdades no plano socioeconômico, cultural, político traduzem-se por diferentes modos de produção e de expressão da pobreza e da exclusão" (BALSA, 2006, p.11). É com esse formato multilateral que a exclusão se apresenta e é também por meio desse enfoque que se pretende discutir no presente trabalho a relação excludente da atuação de gênero no mercado de trabalho formal.

Ademais, é importante ressaltar que não se pode perder de vista a participação dos processos capitalistas no desenrolar do desenvolvimento excludente. Observa-se, nas articulações incertas da 
acumulação flexível, fenômeno atual, uma nítida discrepância na inserção e na permanência de homens e de mulheres no âmbito do mercado de trabalho especificamente.

Em observação ao exposto, o objetivo principal do presente ensaio é entender o processo excludente do mercado de trabalho com enfoque nas questões de gênero, uma vez que esta é uma variável importante nas discussões sobre a produção capitalista. Além disso, como objetivo específico, tem-se a pretensão de avaliar como se dão os processos de ocupação formal no contexto intrinsecamente local, visto que existe na literatura atual uma concentração de atenções para as questões internacionais e nacionais. Nesse ínterim, ainda como objetivos específicos, almeja-se demonstrar diferenças relativas à participação entre os sexos no mercado de trabalho, as distinções de salários e de horas trabalhadas e locus ocupacional.

As análises postas neste texto foram feitas com base nos dados da Relação Anual de Informações Sociais (RAIS) do Ministério da Economia, já que tal base consiste em um censo do mercado de trabalho formal que permite desagregação por municípios, possibilitando, neste caso, a observação do comportamento do mercado de trabalho de Montes Claros (MG). Fato que se faz pertinente na discussão aqui proposta.

\section{A respeito da localidade pesquisada}

Hodiernamente, Montes Claros é uma cidade polo da região do Norte de Minas Gerais, a qual possuía 404.804 habitantes em 2018, segundo estimativas do IBGE. Isso faz dela a sexta maior cidade do Estado, sendo menor apenas do que Belo Horizonte, Uberlândia, Contagem, Juiz de Fora e Betim. Seus serviços de saúde, educação, burocracia pública e do comércio, atendem a uma população de mais de dois milhões de habitantes que povoam o Norte de Minas Gerais. Essa cidade é referência em educação, devido ao número crescente de escolas e cursos universitários. De acordo com o IBGE, em 2012, Montes Claros possuía 117 instituições pré-escolares, 163 escolas de ensino fundamental, 50 de ensino médio, e, segundo o Ministério da Educação (2014), contava ainda com 10 universidades, as quais eram duas com cursos presenciais e oito com ensino a distância, dois centros universitários, ambos ministrando ensino a distância, 18 faculdades e um Instituto Federal.

De acordo com dados da Fundação João Pinheiro (FJP), em 2012, Montes Claros registrou o $10^{\circ}$ maior produto interno bruto (PIB) do Estado de Minas Gerais, somando 5.335 .046 (cinco milhões e trezentos e trinta e cinco mil reais). Embora a economia montes-clarense seja diversificada, tendo boa participação da agropecuária, comércio e indústria, os serviços são o setor de maior destaque. O PIB/serviços foi o sétimo maior do Estado em 2012, fixando-se em 3.492.133, o que representou 65,5\% do PIB municipal total. Já o PIB industrial posicionou a cidade em $20^{\circ}$ lugar no Estado mineiro, também 
em 2012. O PIB per capita em 2012 fixou-se em R $\$ 14.410,63$, valor que coloca o município no $242^{\circ}$ lugar no ranking estadual.

Mesmo não sendo considerado rico, o município de Montes Claros tem vivido um período de crescimento expressivo nos últimos anos. De 1999 até 2012 o PIB brasileiro cresceu 3\% em média, ao passo que, de acordo com dados da Fundação João Pinheiro, o PIB de referido município aumentou $25,2 \%$.

O Índice de Desenvolvimento Humano (IDH) do município em questão é superior ao IDH nacional em todos os anos de avaliação. Em 2010, o IDH montes-clarense foi registrado em 0,770 e o do Brasil fixou-se em 0,727. No mesmo ano, 16 municípios mineiros, incluindo a capital do Estado, tiveram IDH superior ao de Montes Claros. O IDH longevidade é o que mais se destaca dentre as três classificações (renda, longevidade e educação), sendo registrado em 0,868. O IDH renda foi o que se posicionou com menor expressividade dentre os três: 0,707; já o IDH educação, de forma intermediária, foi registrado em 0,744 .

Montes Claros tem atraído uma quantidade expressiva de mão de obra por causa do número significativo de estabelecimentos comerciais, de serviço e das indústrias instaladas. Assim, o mercado de trabalho local reflete sobremodo a tendência nacional, sendo afetado pelas crises e externando concentração de renda e desigualdade.

\section{Gênero e mercado de trabalho na esfera local}

No que se refere às articulações do trabalho, é notória, na contemporaneidade, a flexibilização dos processos produtivos que explicitam o crescimento elevado do setor de serviços, a estagnação ou diminuição do setor industrial, o decrescimento do rendimento médio do trabalhador, a elevação da rotatividade de mão de obra. Enfim, evidencia o estabelecimento do que muitos autores chamam de precarização do trabalho, característica da economia de mercado, como já mencionava Polanyi (2000).

Além das variáveis postas, o crescimento da ocupação feminina, fenômeno almejado por décadas, através de intensas lutas dos movimentos feministas, deveria representar uma conquista. No entanto, no bojo da acumulação flexível, essa variável mostra-se como mais uma evidência da precarização do trabalho.

De acordo com os dados da Relação Anual de Informações Sociais (RAIS) do Ministério do Trabalho, relativos ao período de 1985 a 2015, percebe-se que, em Montes Claros/ MG, os contratos de trabalho entre homens e mulheres tiveram um expressivo crescimento.

Os contratos dos homens cresceram 5,9\%, em média, por ano, enquanto os das mulheres aumentaram 17,9\% anualmente. Como se observa, do ano de 1985 a 2015, há um crescimento relevante 
das mulheres no mercado de trabalho, ou seja, ao longo dos anos tem-se a participação das mulheres efetivamente aumentada mais do que a dos homens. Contudo, mesmo com esse crescimento, as mulheres estão em posição inferior no mercado de trabalho, em comparação ao sexo masculino, como mostra o Gráfico 1.

\section{Gráfico 1 - Emprego formal segundo sexo em Montes Claros - 1985-2015}

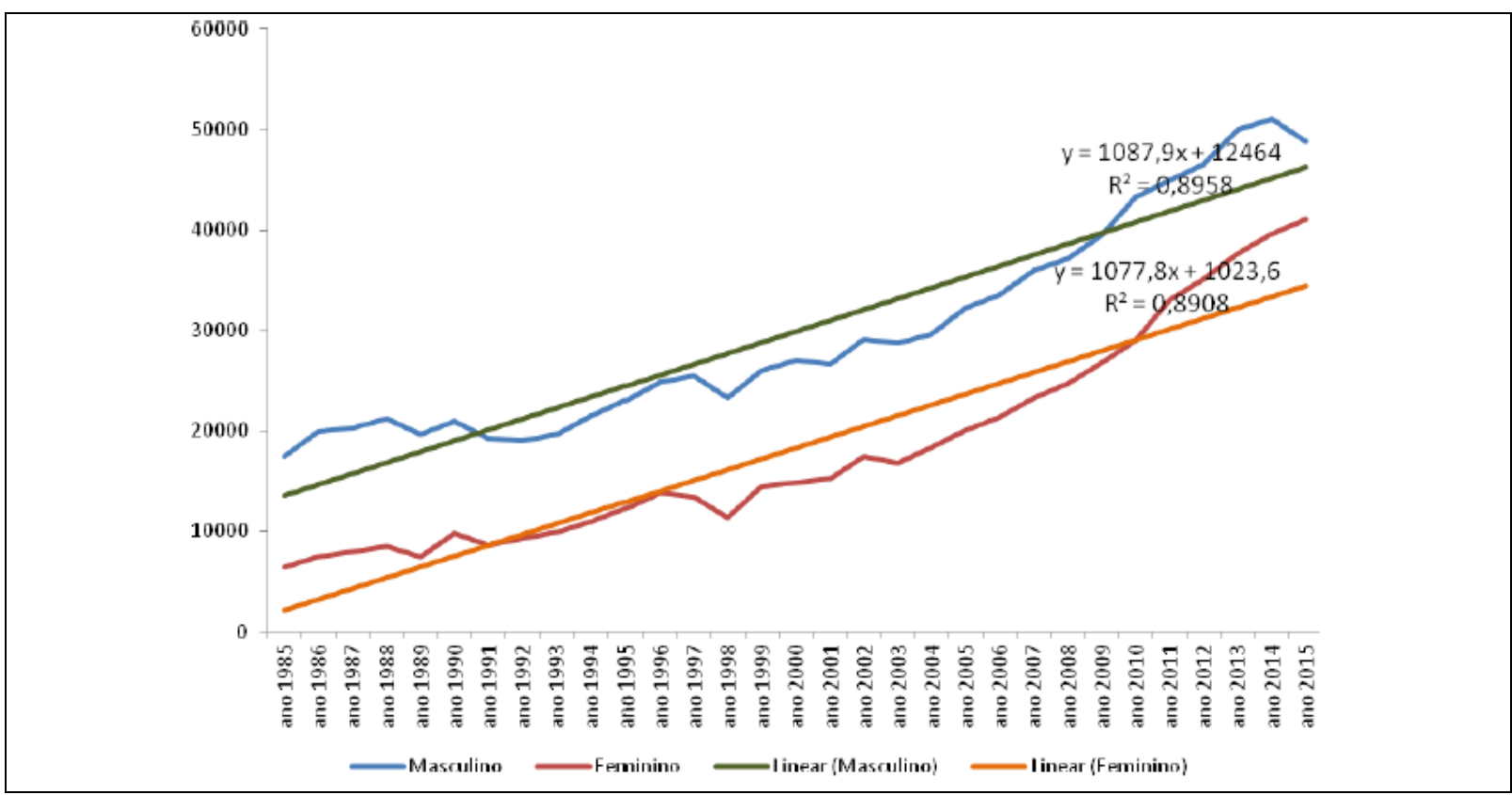

Fonte: RAIS. Elaboração: própria.

O crescimento do número de contratos formais de mulheres traz consigo características perversas do regime flexível de produção capitalista. Isso porque se observa que, embora mais escolarizadas que os homens, as mulheres possuem rendimento médio menor e seus contratos são mais rotativos. O contrato feminino, portanto, representa o cume da flexibilização do mercado de trabalho. Aqui se entende que o capital recorre a essa mão de obra com a finalidade de explorar os recursos humanos mais qualificados, pagando um valor inferior por ele, como será demonstrado adiante.

Hirata (1997) denuncia as discussões a respeito da reestruturação produtiva, concernente à centralidade dessas teorias em relação às observações genéricas sobre a precarização do trabalho, como o que foi dito anteriormente: diminuição do rendimento, crescimento do setor de serviços, rotatividade de mão de obra, dentre outros. A autora entende que as teorias vigentes omitem uma variável de extrema importância: gênero. Para ela, isso se configura em um erro grave, uma vez que, no contexto do mercado de trabalho flexível, as mulheres percebem de forma mais drástica as dimensões perversas do processo de reestruturação produtiva. Hirata aponta que as variáveis de instabilidade são intensificadas quando observadas comparativamente entre homens e mulheres. 
De forma empírica, Hirata (2018, p.17) ilustra a constatação acima, asseverando o seguinte:

O desemprego feminino é maior do que o masculino na maioria dos países industrializados, e as mulheres são majoritárias no desemprego oculto pelo desalento (INSEE, Enquête Emploi, 2005.a). Na França, em 2012, a taxa de desemprego feminina é, em 2012, ligeiramente mais elevada $(10 \%)$ que a taxa de desemprego masculina $(9,7 \%)$, mas esse diferencial foi mais importante em todos os anos passados, chegando a ser de 4\% (em 1980 e em 1990); e de 3\% (em 2000).

O que está posto é que, se de forma genérica os processos atuais enfrentados pelo mercado de trabalho no mundo capitalista trazem fatores instáveis de articulações do trabalho, quando se analisa especificamente a questão do trabalho e gênero, percebe-se que as formas de contratos e salários são ainda mais exploradoras, flexíveis, instáveis e excludentes.

O problema da diferenciação, ou discriminação, entre os sexos, evidenciada por esse processo de flexibilização é notório também no Brasil. De acordo com Bruschini:

[...] o trabalho feminino não deixa de ser caracterizado como mais precário em relação ao masculino. Ao contrário, há várias evidências de que a desigualdade de gênero continua a demarcar o mercado de trabalho brasileiro. Uma delas pode ser encontrada em informações sobre o local no qual os trabalhadores desempenham suas atividades. Nesse caso, constata-se que, embora mais da metade das ocupadas, como ocorre com os seus colegas, trabalhem em lojas, oficinas, ou escritórios, um percentual considerável delas trabalha no próprio domićlio $(12,4 \%)$ ou no domicílio do patrão $(17,5 \%)$, cifras bem mais elevadas do que a dos trabalhadores que se encontram na mesma situação (BRUSCHINI, 2000, p.31).

Se aprofundarmos as observações a respeito dos espaços de trabalho relativos a homens e mulheres, extrapolando as atenções pautadas nos setores de atividade econômica, podemos identificar o fenômeno que Neves (2000) chama de "guetos ocupacionais", em que o crescimento da ocupação de mulheres é claramente identificado em postos de trabalho muito bem definidos. No caso de Montes Claros, em 1985, as mulheres eram encontradas trabalhando na indústria de calçados, nos serviços de alojamento, manutenção, reparação, além do ensino.

Outra questão que agrava a situação do mercado de trabalho e do gênero diz respeito à estratificação por renda. De acordo com estudos realizados por Lavinas (1996), as disparidades inerentes às questões de emprego são ainda mais aguçadas quando se compara a população pobre e a não pobre. Essa autora afirma que a segregação por renda é mais marcante do que a própria segmentação relacionada a gênero (LAVINAS, 1994).

No entanto, é notório que a situação das mulheres pobres é ainda pior do que a dos homens pobres. Segundo suas observações:

As mulheres, pobres e não pobres, apresentam rendas inferiores às masculinas, taxas de atividades menores, jornadas de trabalho reduzidas porque não são ainda uma força de trabalho verdadeiramente livre e móvel, evidenciando constrangimentos decorrentes de seu lugar na divisão sexual do trabalho doméstico (Idem, 1996, p.479). 
Bruschini (2000) vai além das explicações de Lavinas. Para a primeira, não é somente a falta de liberdade e de mobilidade das mulheres que as incumbe de atuar num mercado de trabalho específico, inferior, rotativo, insalubre e ainda mais precário, comparativamente ao dos homens. Essas práticas de discriminação sexual no Brasil estão fundamentalmente ligadas a um modelo de sociedade patriarcal, que define as funções laborais com base em uma divisão do trabalho em que o papel feminino deve ser representado no cenário doméstico.

De acordo com Bruschini (2000):

[...] a manutenção de um modelo de família patriarcal, segundo o qual cabe às mulheres as responsabilidades domésticas e socializadoras, bem como a persistência de uma identidade construída em torno do mundo doméstico condicionam a participação feminina no mercado de trabalho a outros fatores além daqueles que se referem à sua qualificação e à oferta de emprego, como no caso dos homens. A constante necessidade de articular papéis familiares e profissionais limita a disponibilidade das mulheres para o trabalho, que depende de uma complexa combinação de características pessoais e familiares, como o estado conjugal e a presença de filhos, associados à idade e à escolaridade da trabalhadora, assim como à característica do grupo familiar, como ciclo de vida e à estrutura familiar. Fatores como estes afetam a participação feminina, mas não a masculina, no mercado de trabalho (BRUSCHINI, 2000, p.17).

A participação das mulheres no mercado de trabalho pode ser observada por meio de um prisma extremamente estratificado. Desse modo, o quadro do emprego feminino se posiciona, em regra geral, da seguinte forma: as mulheres estão empregadas em atividades bem específicas, são encontradas nos campos administrativos, educacionais e domésticos; possuem salários inferiores, seus contratos são ainda mais flexíveis que os dos homens. Em outras palavras:

[...] apesar da crescente participação da mulher no mercado de trabalho, pode-se detectar, nas diferentes análises a segmentação por gênero no mercado de trabalho com a concentração feminina em determinados guetos ocupacionais e, além disso, a concentração de mulheres em postos de trabalho mais instáveis e de piores remunerações (NEVES, 2000, p.174).

As desigualdades entre homens e mulheres no mercado de trabalho retratam apenas uma forma de desigualdade de gênero. Deve-se mencionar que as desigualdades se mostraram naturais aos olhos das diversas sociedades, inclusive da capitalista ocidental, contudo, não o são. As desigualdades de gênero são socialmente impostas e constituídas historicamente.

Quando se olha para diferenças salariais entre homens e mulheres, para a disparidade dos cargos que ocupam, dos espaços aos quais são alocados e alocadas, vê-se apenas uma forma de diferenciação de gênero dentre tantas outras que posicionam os homens como indivíduos superiores e as mulheres como 
pessoas inferiores. Tudo isso faz parte de um esquema simbólico criado socialmente a partir de percepções que são reproduzidas como convencionais ou naturais, entretanto:

Esses esquemas de pensamento, de aplicação universal, registram como que diferenças de natureza, inscritas na objetividade, das variações e dos traços distintivos (por exemplo, em matéria corporal) que eles contribuem para fazer existir, ao mesmo tempo que as "naturalizam", inscrevendo-as em um sistema de diferenças todas igualmente naturais em aparência; de modo que as previsões que elas engendram são incessantemente confirmadas pelo curso do mundo (BOURDIEU, 2002, p.15).

As relações desfavoráveis às mulheres em comparação aos homens são explicadas por Foucault (2019, p.112), segundo mecanismos históricos de poder, in verbis, "Nas relações de poder, a sexualidade não é o mecanismo mais rígido, mas um dos dotados de maior instrumentalidade: utilizável no maior número de manobras, podendo servir [...] às mais variadas estratégias". Fato o qual denota a mulher como um instrumento de controle social que, nesse aspecto, a relação entre sexos evidencia o homem como o agente do poder, logo, do controle, e a mulher como seu objeto.

Isso mostra a existência de diversas desigualdades entre homens e mulheres, o que se reverbera também no mercado de trabalho. Em suma, não é natural a realidade de diferença de salários, da segmentação sexual entre cargos e funções, além da diferença entre as horas trabalhadas no mercado de trabalho formal. Esses fatores são construções sociais ligadas às relações de poder inerente à sexualidade.

\section{Gráfico 1 - Participação percentual no mercado de trabalho segundo sexo em Montes Claros -} 1985-2015.

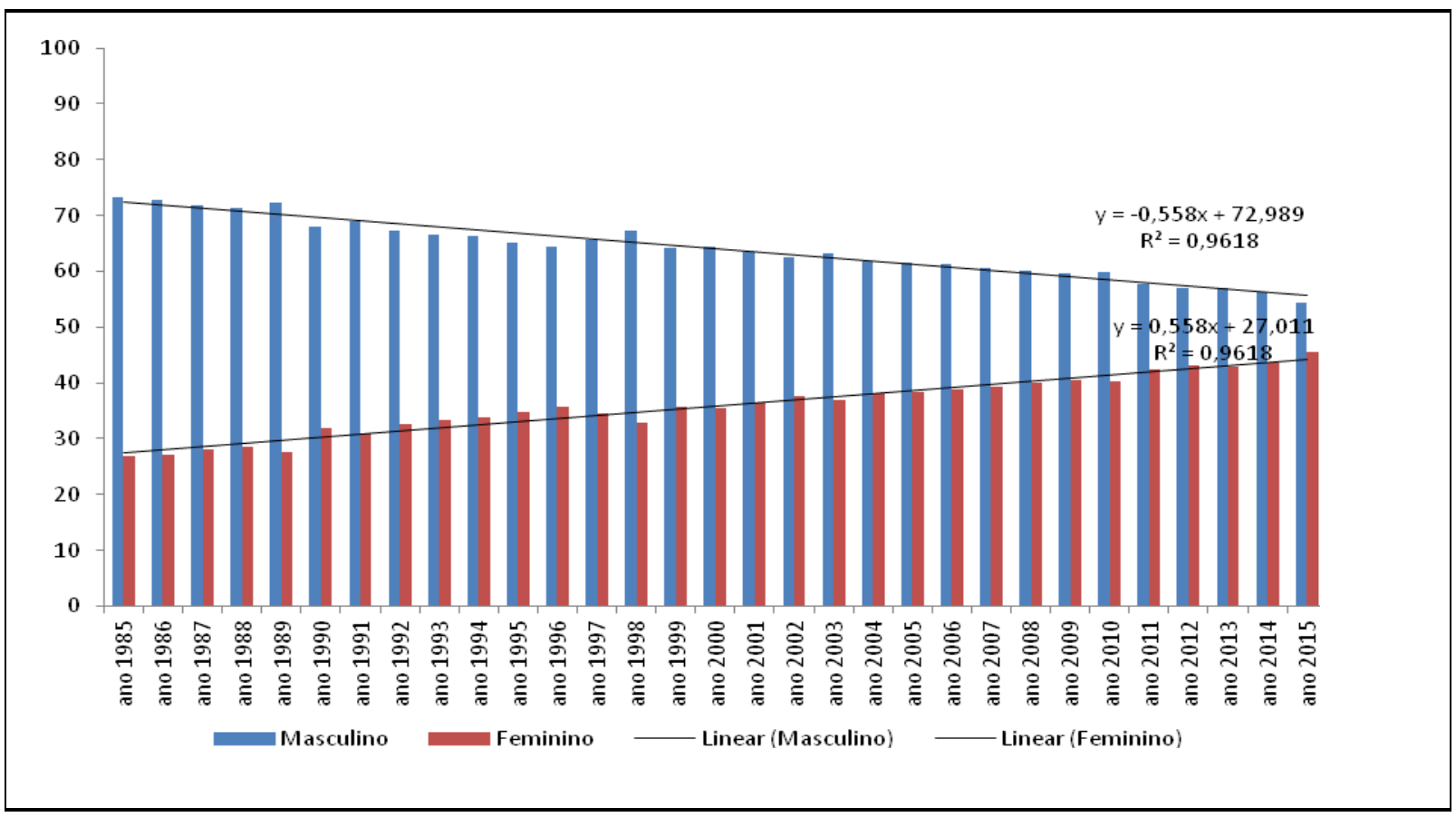

Fonte: RAIS. Elaboração: Própria. 
Avaliando a participação percentual entre homens e mulheres, nota-se que a participação dos contratos masculinos diminui linearmente em relação às mulheres. Em 1985, as mulheres ocupavam 26,8\% do total das vagas formais de emprego. Em 2015, elas passaram a ocupar 45,64\%. Durante todo o período, a participação percentual feminina, nos empregos formais, aumenta em média $0,56 \%$. Isso significa que, se a mesma tendência se mantiver, no ano 2022, a participação percentual das mulheres no mercado de trabalho formal em Montes Claros, será de aproximadamente 50,0\%.

Gráfico 2 - Emprego formal segundo sexo em Montes Claros, indústria, construção civil, serviços e comércio - 1985-2015

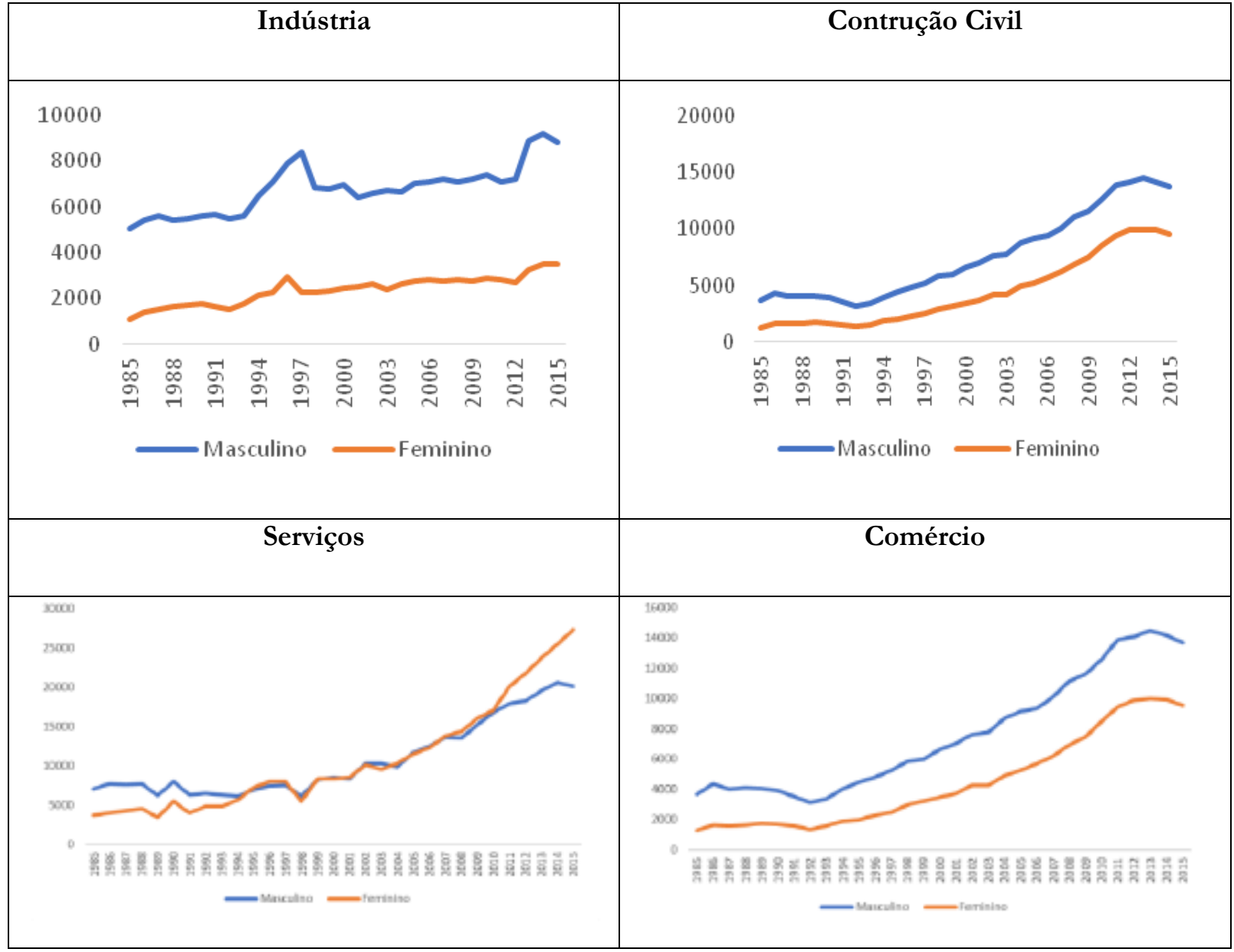

Fonte: RAIS/MTE. Elaboração: Própria.

Quando se olha para os setores de atividade econômica, revela-se uma distribuição setorial dos sexos. A força de trabalho formal feminina estava presente em 17,5\% do total de trabalhadores da indústria em 1985 e se expandiu para 28,4\% em 2015. A despeito do aumento percentual feminino na indústria, a participação das trabalhadoras ainda é restrita nesse setor. Tal fenômeno encontra-se mais acentuado na construção civil. Em 1985, as mulheres representavam 0,4\% do total de trabalhadores desse setor, já, em 2015, a participação das mulheres se elevou para 5,1\% apenas.

Observa-se que, no setor da construção civil, o crescimento das mulheres não foi tão relevante quanto em outros setores do mercado, pois ainda nele há prevalência expressiva dos homens. A diferença 
na participação de trabalhadores e trabalhadoras na indústria e na construção civil, ao longo do período estudado em Montes Claros, pode ser evidenciada no Gráfico 2.

Embora as mulheres ainda sejam a minoria no setor de comércio em Montes Claros, sua partição percentual, nesse setor, aumentou de 26,1\% em 1985, para 40,1\% em 2015. As trabalhadoras tiveram um aumento significativo no referido setor a despeito do destaque que os homens mantiveram em relação a elas quanto à participação na força de trabalho formal.

O setor de serviços se difere dos demais porque o crescimento aguçado dos contratos femininos fez com que o número de trabalhadoras suplantasse o de trabalhadores. As mulheres ocupavam 34,3\% das vagas formais em 1985 e passaram a ocupar 57,5\% em 2015. No setor de serviços, observa-se que as mulheres tiveram um crescimento relevante a ponto de ocasionar algo que não ocorreu nos outros setores: a feminização da força de trabalho.

Tabela 1 - Ocupação de homens e mulheres segundo subgrupos da Classificação Brasileira de Ocupações em Montes Claros (MG) - 2015

\begin{tabular}{l|c}
\hline \multicolumn{1}{c}{ Ocupação } & Freq. \\
\hline Trabalhadores de informações ao publico & 4946 \\
Escriturários em geral, agentes, assistentes e auxiliares administrativos & 4430 \\
Vendedores e demonstradores & 4263 \\
Trabalhadores dos serviços de hotelaria e alimentação & 3286 \\
Trabalhadores nos serviços de administração, conservação e manutenção de edifícios e. & 2729 \\
Técnicos da ciência da saúde humana & 2070 \\
Caixas, bilheteiros e afins & 1906 \\
Professores de nível superior na educação infantil e no ensino fundamental & 1852 \\
\hline Trabalhadores dos serviços de saúde & 1007 \\
\hline
\end{tabular}


Tabela 2 - Ocupação de homens e mulheres segundo subgrupos da Classificação Brasileira de Ocupações em Montes Claros (MG) - 2015 (continuação)

\section{Masculino}

\begin{tabular}{l|r}
\hline \multicolumn{1}{c|}{ Ocupação } & Freq. \\
\hline Vendedores e demonstradores & 4550 \\
Condutores de veículos e operadores de equipamentos de elevação e de movimentação & 3333 \\
Escriturários em geral, agentes, assistentes e auxiliares administrativos & 2623 \\
Trabalhadores nos serviços de proteção e segurança & 2270 \\
Trabalhadores da construção civil e obras & 2181 \\
Trabalhadores nos serviços de administração, conservação e manutenção de edifícios e & 1838 \\
Ajudantes de obras & 1599 \\
Embaladores e alimentadores de produção & 1422 \\
Trabalhadores de informações ao publico & 1322 \\
Escriturários de controle de materiais e de apoio à produção & 1204 \\
\hline FON
\end{tabular}

FONTE: RAIS. Elaboração: Própria.

Aqui está clara a segregação setorial dos sexos. Pode-se dizer que a indústria e a construção civil se mantêm ainda como setores masculinos, enquanto o setor de serviços abre mais espaço para as mulheres e o comércio se apresenta como setor intermediário. Tal fenômeno denota o conceito de guetos ocupacionais discutido por Neves (2000). Importante mencionar que tais guetos ocupacionais não se mostram apenas por meio dos setores de atividade econômica, mas também a partir das funções desempenhadas. Como denotado pela Tabela 1, existem profissões ou atividades tipificadas como femininas e outras como masculinas. Esse fato ratifica a construção social do poder e do controle masculinos, mencionada por Foucault (2009).

A Tabela 1 evidencia as dez ocupações mais frequentes para cada sexo. É importante ressaltar que as ocupações de: trabalhadores de serviços de hotelaria, técnicos da ciência da saúde humana, caixas bilheteiros e a fins, professores de nível superior na educação infantil e no ensino fundamental, trabalhadores dos serviços de saúde e professores de nível médio na educação infantil, no ensino fundamental e no profissional são profissões que aparecem na lista feminina, não na masculina.

De outro modo, as ocupações de condutores de veículos e operadores de equipamentos de elevação e de movimentação, trabalhadores nos serviços de proteção e segurança, trabalhadores da 
construção civil e obras, ajudantes de obras e embaladores e alimentadores de produção são mencionadas apenas na lista masculina.

Entre as dez ocupações mais frequentes das mulheres, cinco não constam entre as dez mais frequentes entre os homens e, quanto às dez mais frequentes entre os homens, seis não aparecem na lista das mulheres. Esse fenômeno evidencia a segmentação sexual do trabalho no que diz respeito a funções socialmente definidas como tipicamente femininas ou tipicamente masculinas.

Pode-se observar que as ocupações mais frequentes entre os homens, e que não se vinculam ao grupo das mulheres, são exatamente aquelas ligadas à força física. Ao contrário, as funções mais frequentes entre as mulheres, não evidentes na lista masculina, dizem respeito a trabalhos ligados ao cuidado, campo alocado às mulheres, no âmbito da divisão sexual do trabalho (HIRATA, 2006).

No que diz respeito a rendimento, assim como na avaliação da participação de pessoal formalmente ocupado, identifica-se uma redução das diferenças entre sexos, não obstante a situação ainda privilegiada dos homens. Em 1987, a diferença da média salarial entre homens e mulheres foi superior a um salário mínimo à época. Naquele ano, os homens ganharam em média 3,1 salários mínimos e as mulheres receberam 2,1 salários. Já em 2007, a diferença salarial entre ambos os sexos foi quase insignificante, 0,06 salário. Tal diferença reduziu em média 0,03 salários por ano.

Gráfico 3 - Média salarial de homens e mulheres em Montes Claros - 1985 a 2015

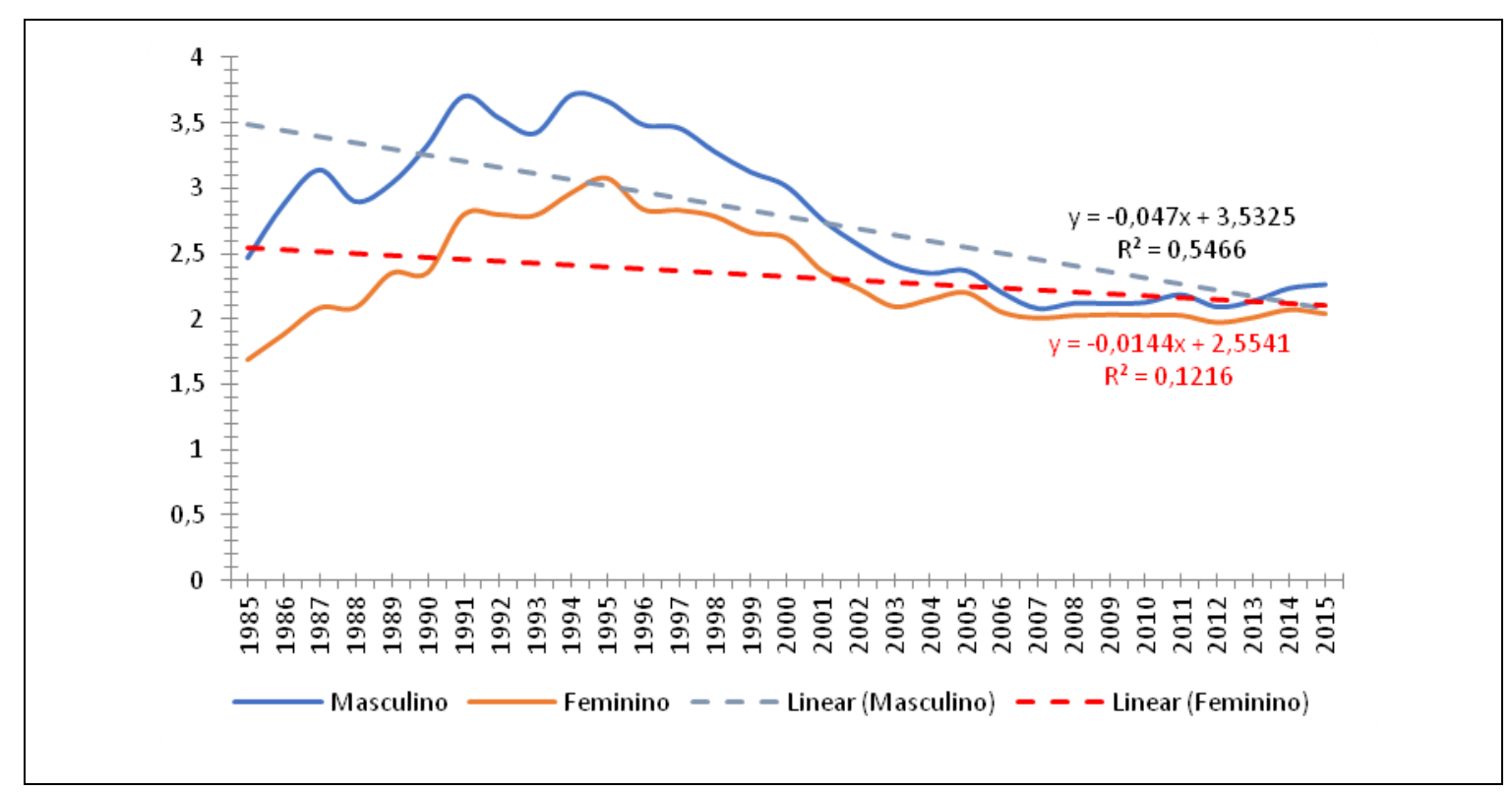

Fonte: RAIS. Elaboração: Própria.

Porém, é importante destacar que, no caso de Montes Claros, a diminuição da diferença salarial entre sexos se deu muito mais pela redução da média dos salários dos homens do que devido ao aumento da média dos salários das mulheres. Isso porque, em ambos os sexos, houve redução do valor médio 
salarial entre os anos 1985 e 2015. Contudo, enquanto os salários femininos diminuíram em valor relativo a 0,01 salário mínimo por ano, os masculinos reduziram 0,04 anualmente no período de 1985 a 2015. Conforme a análise, houve a diminuição de ambos os salários, ou seja, ao longo dos anos, a média tanto dos homens quanto das mulheres diminuiu. Mas, ainda assim, ambos não possuem igualdade salarial, pois os homens seguem com rendimentos superiores.

A redução da disparidade salarial entre trabalhadores e trabalhadoras ocorreu de forma muito expressiva entre os anos 2003 e 2013. Já em 2014 e 2015, contudo, é possível notar uma elevação do distanciamento entre os rendimentos salariais médios dos sexos.

A distância salarial se mostra incoerente quando comparada à escolaridade dos trabalhadores e das trabalhadoras. É possível constatar que existe uma participação maior de mulheres com escolaridade elevada e de homens com escolaridade inferior, ou seja, entre os contratos com alta escolaridade as mulheres são a maioria, de outro modo, os contratos masculinos são numericamente mais representativos nas faixas de escolaridade inferiores. Por exemplo, no grupo dos analfabetos, os homens representam $77,6 \%$ dos trabalhadores formalmente ocupados. No outro extremo, quanto aos trabalhadores que possuem doutorado, $53,4 \%$ são mulheres.

Gráfico 4 - Participação percentual entre homens e mulheres segundo faixa de escolaridade no mercado de trabalho em Montes Claros (MG) - 2017

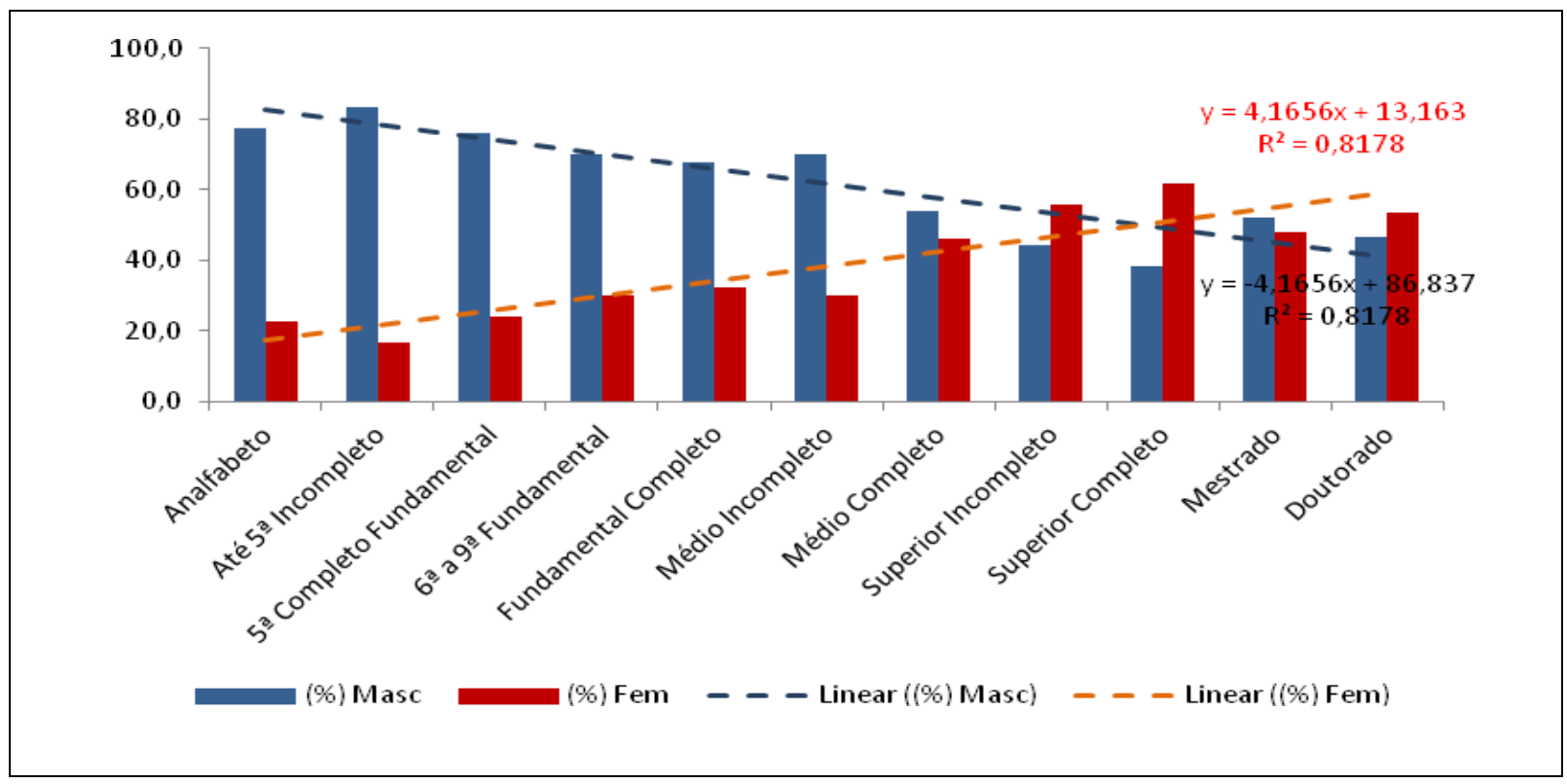

FONTE: RAIS. Elaboração: Própria.

Com base na análise linear, observa-se que, na escala das faixas de escolaridade, a participação percentual masculina diminui em média 4,16\%, quando se eleva uma faixa de instrução. Os dados dos Gráficos 3 e 4 demonstram que as mulheres se escolarizam mais que os homens, mas, em termos gerais, a 
escolaridade elevada pode não refletir em altos salários. Por isso a incoerência se dá devido ao fato de as mulheres atuarem com maior expressão no grupo dos mais escolarizados, mas se destacarem também no grupo dos que possuem média salarial inferior.

Mais uma vez fica evidente a explicação da manutenção de poder mencionada por Foucault (2009). Mesmo mais escolarizadas, as mulheres se submetem ao poder masculino no que se refere a cargos e funções específicas, geralmente se vinculando a atividades que pagam salários inferiores, ao contrário dos homens. Tal fenômeno não se efetiva como verdadeiramente incoerente porque é explicado pela relação de gênero. Historicamente os homens têm se posicionado em patamares superiores aos alcançados pelas mulheres. Como dito antes, tal tendência tem diminuído, mas não o suficiente para extinguir a desigualdade persistente entre os sexos.

Quanto às horas destinadas ao emprego, de 1985 a 2015, a jornada média de trabalho semanal dos homens em Montes Claros foi 42,3 horas e das mulheres foi 39,7. Observa-se que, na média de horas trabalhadas, os homens laboram mais de duas horas que as mulheres por semana.

Gráfico 5 - Média de horas trabalhadas entre homens e mulheres em Montes Claros (MG) - 1995 2017

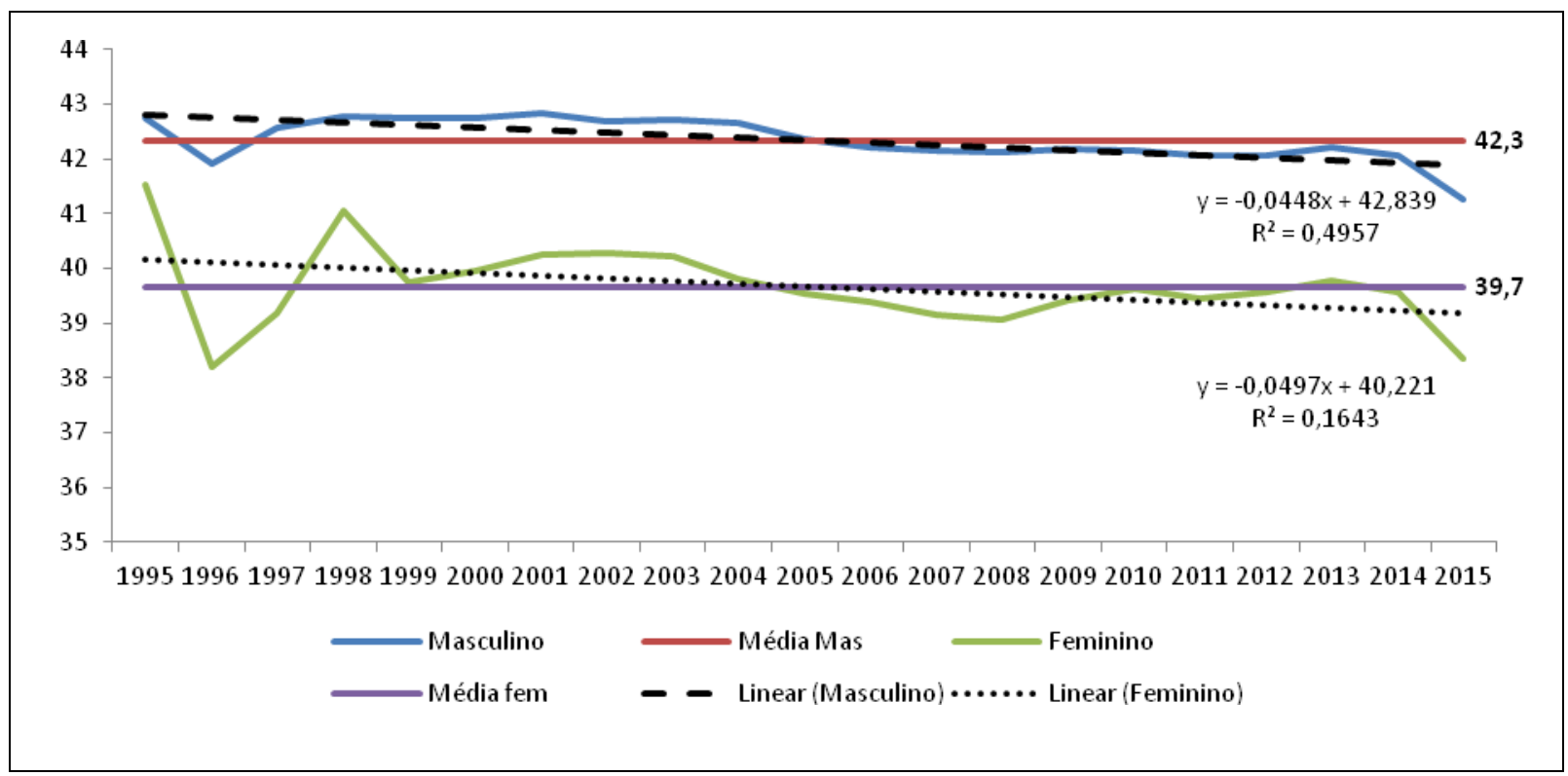

FONTE: RAIS. Elaboração: própria.

Tal fenômeno também impacta os salários. Isso porque, se os homens têm uma jornada de trabalho formal superior à das mulheres, tendem então a auferirem rendimentos superiores. Para além da alocação dos cargos e funções, como dito anteriormente, uma possível explicação para tal disparidade se dá pelo fato de as mulheres despenderem mais tempo em atividades domésticas do que os homens. Geralmente elas cuidam mais das tarefas demandadas por seus filhos do que os homens. As pessoas 
idosas, ou que possuem alguma limitação física, geralmente são assistidas por mulheres quando estão sob o cuidado da família.

Tais fatores obrigam as mulheres a abdicarem de atividades remuneradas ou optarem por atividades com jornada de trabalho inferior. Isso impacta na participação das mulheres no mercado de trabalho, tornando os contratos femininos numericamente inferiores aos masculinos na jornada de trabalho, compelindo-as também a receberem salários menores.

É claro que a destinação dos cuidados domésticos às mulheres não é um fim em si mesmo, mas está ligada ao estigma social historicamente construído e à delimitação de espaços também demarcados pela história, a qual destinou os ambientes públicos e externos aos homens, enquanto os locais privados e fechados foram resguardados para as mulheres.

Tal discussão se liga aos espaços, aos locais da atuação segundo gênero. A respeito disso, Priore (2011, p.624) menciona:

Lugar de mulher é o lar [...] a tentativa da mulher moderna de viver como um homem durante o dia, e como uma mulher durante a noite, é a causa de muitos lares infelizes e destroçados. [...] Felizmente, porém, a ambição da maioria das mulheres ainda continua a ser o casamento e a família. Muitas, no entanto, almejam levar uma vida dupla: no trabalho e em casa, como esposa, a fim de demonstrar aos homens que podem competir com eles no terreno, o que frequentemente as leva a um eventual repúdio de seu papel feminino. Procurar serem à noite esposa e mãe perfeitas e funcionária exemplar durante o dia requer um esforço excessivo [...]. O resultado é geralmente a confusão e a tensão reinantes no lar, em prejuízo dos filhos e da família.

Deve-se ainda ressaltar que a desigualdade existente entre homens e mulheres no mercado de trabalho persiste a despeito da legislação, uma vez que o Brasil é signatário de Convenções Internacionais e possui na sua própria legislação tanto constitucional, como infraconstitucional, a expressa proibição de tratamentos desiguais no tocante à variável sexo. A título de exemplo, a Convenção 111 que aborda sobre a discriminação no trabalho, dispõe no Art. $1^{\circ}$ :

[...] discriminação no trabalho como toda distinção, exclusão ou preferência fundada na raça, cor, sexo, religião, opinião política, ascendência nacional, origem social ou qualquer outra condição, que tenha por efeito destruir ou alterar a igualdade de oportunidades ou de tratamento em matéria de emprego ou profissão (BRASIL, Convenção 111 , Art. $1^{\circ}$.

A própria Constituição da República Federativa do Brasil (CRFB) de 1988 destitui qualquer forma de discriminação nas relações entre as pessoas, evidenciando a igualdade jurídica entre os cidadãos. No 
que diz respeito às discriminações entre sexo, o texto constitucional externa no Art. 5', Inciso I: "homens e mulheres são iguais em direitos e obrigações, nos termos desta Constituição” (BRASIL, CRFB, 1988). De igual modo, a Consolidação das Leis Trabalhistas, veda qualquer possibilidade de discriminação referente ao mesmo assunto, proibindo, por exemplo, diferença salarial e recusa de emprego por distinção de sexo.

Como demonstrado, a despeito do que se prevê nos dispositivos legais, a diferença entre homens e mulheres no mercado de trabalho ainda é marcante na atualidade. Fato este evidenciado pelos dados oficiais referentes ao caso específico do município pesquisado, mas que denotam a realidade vivenciada no Brasil e na maior parte dos países.

\section{Considerações finais}

A respeito das perguntas norteadoras, postas no início deste texto, se chaga à seguinte conclusão: Houve expressivo crescimento do número de mulheres no mercado de trabalho formal em Montes Claros (MG). Tal se mostrou mais robusto do que a elevação dos contratos dos homens, contudo, as mulheres ainda são minoritárias em relação aos homens na atuação formal do mercado de trabalho.

As constatações de Helena Hirata sobre a segregação na divisão sexual do trabalho e as observações de Magda Neves referentes aos guetos ocupacionais são muito visíveis na pesquisa em foco. As mulheres se posicionam como a maioria na participação do mercado de trabalho formal apenas no setor de serviços. Quanto às ocupações desempenhadas por elas, percebe-se o destaque daquelas ligadas ao cuidado, algo também evidenciado por Pierre Bourdieu.

No tocante aos salários, por mais que tenha havido uma redução acentuada da diferença salarial entre os sexos, tal redução se deu devido ao decrescimento da média salarial dos homens e não pela elevação do salário das mulheres. Ainda assim, os homens continuam percebendo maiores rendimentos do que as mulheres, em média.

Em suma, o mercado de trabalho formal em Montes Claros (MG) evidencia claras diferenças entre sexos. Isso está posto no quadro de pessoal ocupado, na alocação setorial de trabalhadores e trabalhadoras, nos salários percebidos e nas horas trabalhadas. É notório, contudo, que historicamente tais diferenças têm diminuído, mas não o suficiente para afirmar que o mercado de trabalho é um ambiente social, democrático e não discriminador. Ao contrário, os dados mostram que, a despeito da redução das diferenças, os trinta anos que foram observados revelaram que os espaços não são de igual modo receptivos para homes e mulheres. Há descompassos que devem ser monitorados, avaliados e sanados. 
Para tanto, se faz imperativa a atuação do Estado na formulação de políticas que objetivem a resolução dessas e de outras desigualdades envolvendo a variável sexo. Entende-se que, uma vez definida a agenda de políticas direcionadas à erradicação das disparidades sexuais a médio e longo prazo, será possível colher os frutos da ação estatal. Todavia, antes de se perguntar por que tal agenda não é efetivada, deve-se avaliar a macroagenda do Estado e definir outra pergunta: a erradicação das discrepâncias entre sexos no mercado de trabalho faz parte das prioridades atuais do Estado? Esse é um relevante tema para outros estudos.

\section{Referências}

BALSA, Casimiro. Conceitos e Dimensões da Pobreza: Uma Abordagem Trasnacional. In: BONETI, Lindomar Wessler; SOULET, Marc-Henry (Orgs). Conceitos e Dimensões da Pobreza e da Exclusão Social. Ijuí:Unijuí, 2006.

BOURDIEU, Pierre. A dominação masculina. 2.ed. Trad. de Maria Helena Kühner. Rio de Janeiro: Bertrand Brasil, 2002.

BRASIL. Consolidação das leis do trabalho - CLT e normas correlatas. Brasília: Senado Federal, Coordenação de Edições Técnicas, 2017.

BRASIL. Constituição da República Federativa do Brasil. Brasília, Congresso Federal, 1988.

BRASIL. Decreto $\mathrm{N}^{\mathrm{o}}$ 62.150, de 19 de janeiro de 1968. Convenção $\mathbf{N}^{\mathbf{0}} 111$ da OIT sobre discriminação em matéria de emprego e profissão. Brasília, DF, janeiro 1968. Disponível em <http://www.planalto.gov.br/ccivil_03/decreto/1950-1969/d62150.htm> Acesso em: 27 de julho de 2019.

BRASIL, Ministério do Trabalho. Bases de dados da Relação Anual de Informações Sociais. Brasília, 2017.

BRUSCHINI, Cristina. Gênero e Trabalho no Brasil: Novas Conquistas ou Resistência da Discriminação? In: ROCHA, Maria Isabel Baltar. (Org.). Trabalho e Gênero: Mudanças, Permanências e Desafios. São Paulo: 34, 2000. p.13-58.

FOUCAULT, Michel. História da sexualidade: a vontade de saber. V. 1. 8.ed. Rio de Janeiro: Paz e Terra, 2019.

HIRATA, Helena. Reestruturação Produtiva, Trabalho e Relações de Gênero. In: Revista Latinoamericana de Estudos do Trabalho. Ano 3, nº: 1997.

Divisão Sexual do Trabalho. São Paulo: 2006.

16, no29, 2018 .

Gênero, patriarcado, trabalho e classe. In: Revista Trabalho Necessário. Rio de Janeiro: Ano

LAVINAS, Lena. As Mulheres no Universo da Pobreza: O Caso Brasileiro. In. Estudos Feministas. N²: 1996.

NEVES, Magda de Almeida. Reestruturação Produtiva, Qualificação e Relações de Gênero. In: ROCHA, Maria Isabel Baltar. (Org.). Trabalho e Gênero: Mudanças, Permanências e Desafios. São Paulo: 34, 2000. p. 171- 185. 
POLANYI, Karl. A grande transformação: as origens de nossa época. 2.ed. Rio de Janeiro: Elsevier, 2000.

PRIORE, Mary Del. História das mulheres no Brasil. 2.ed. São Paulo: Contexto, 1997.

Recebido em: agosto de 2019. Aprovado em: dezembro de 2019. 